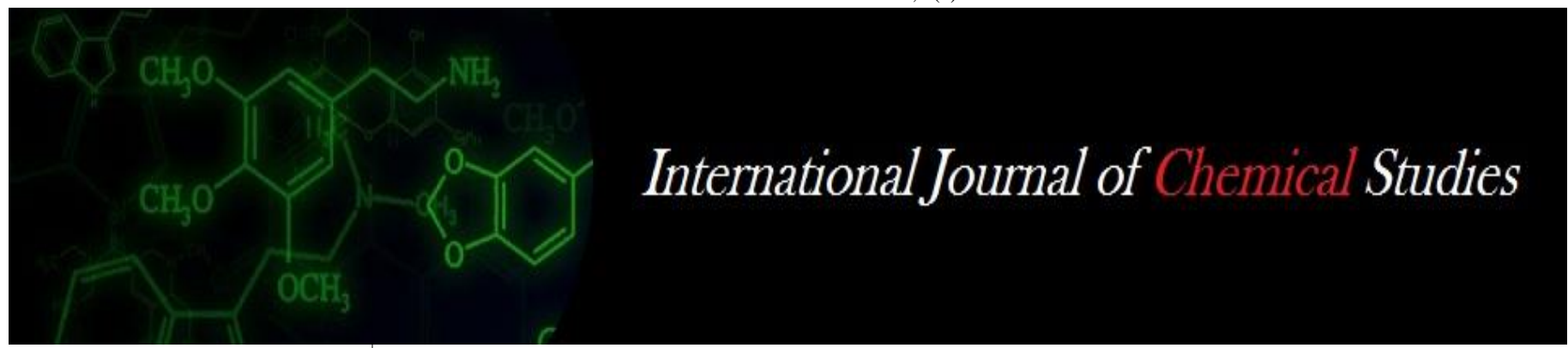

P-ISSN: 2349-8528

E-ISSN: 2321-4902

IJCS 2020; 8(1): 1701-1708

(C) 2020 IJCS

Received: 01-11-2019

Accepted: 03-12-2019

L Gowthami

College of Horticulture,

Dr. Y.S.R. Horticultural

University, Anantharajupeta,

Railway Kodur (Mandal),

Kadapa District,

Andhra Pradesh, India

V Vijaya Bhaskar

College of Horticulture,

Dr. Y.S.R. Horticultural

University, Anantharajupeta,

Railway Kodur (Mandal),

Kadapa District,

Andhra Pradesh, India
Corresponding Author:

L Gowthami

College of Horticulture,

Dr. Y.S.R. Horticultural

University, Anantharajupeta,

Railway Kodur (Mandal),

Kadapa District,

Andhra Pradesh, India

\section{Mechanisms required to overcome the dormancy in ornamental plants}

\section{Gowthami and V Vijaya Bhaskar}

DOI: https://doi.org/10.22271/chemi.2020.v8.i1y.8506

\begin{abstract}
Dormancy is a temporary suspension of visible growth of any plant structure containing a meristem. It is an indigenously controlled but environmentally imposed temporary suspension of growth accompanied by reduced metabolic activity. It is a state in which viable seed fails to germinate even under favourable conditions of moisture, temperature and oxygen for vegetative growth. Seed dormancy and bud dormancy in ornamental plants can be overcome by different methods which are discussed in detail in the present review article.
\end{abstract}

Keywords: Dormancy, rest, quiescence, seed dormancy, bud dormancy

\section{Introduction}

Dormancy is a temporary suspension of visible growth of any plant structure containing a meristem. It is an indigenously controlled but environmentally imposed temporary suspension of growth accompanied by reduced metabolic activity. It is a state in which viable seed fails to germinate even under favourable conditions of moisture, temperature and oxygen for vegetative growth. Dormancy may last only for a few days (or) years (or) more in some seeds. It is a block to germination which has evolved differently across the species through adaptation to the prevailing environment, so that germination occurs when conditions for establishing a new plant generation are likely to be suitable. It should not just be associated with the absence of germination rather it is a characteristic of the seed that determines the conditions required for germination.

Dormancy in seed or bud occurs due to wide range of reasons that often overlap, producing conditions in which definitive categorization is not clear. Compounding this problem is that the same seed that is dormant for one reason at a given point may be dormant because of another reason at a later point. Some seeds fluctuate from periods of dormancy (viable seeds that do not germinate are said to be dormant) to non-dormancy and despite the fact that a dormant seed appears to be static (or) inert, in reality they are still receiving and responding to environmental cues. Seed dormancy is an innate seed property, which defines the environmental conditions that must be met before the seed can germinate. The intrinsic molecular mechanisms that determine dormancy have an embryo and a coat component. In a population of seeds, some may exhibit deeper dormancy than others. Those with shallow dormancy may germinate over a wide range of temperatures, while those with deeper dormancy may not germinate (or) will germinate only at the optimal temperature (i.e., conditional dormancy). Bulbs, corms and tubers also show dormancy apart from seed and bud dormancy.

Dormancy can be distinguished from other terms such as Rest and Quiescence, which reflects states of inhibited development due to an unfavorable environment. Rest is a condition where the seed (or) bud is under endogenous conditions. Quiescence is a condition where the seed (or) bud is under exogenous conditions like water supply, temperature, etc., Once dormancy is broken there may be a brief period of quiescence followed by rehydration of the bud leading to an increase in fresh weight, increased respiration, increased promoters, activation of enzyme systems leading to a breakdown of storage materials and growth of the bud into a shoot. 


\section{Phases of dormancy}

\section{a) Induction}

This phase is characterized by a striking decrease in promoter and an increase in inhibitor activity. This phase may be triggered (or) affected by environmental factors such as temperature and light.

\section{b) Maintenance}

During this phase, general metabolism and endogenous promoters are very low while levels of inhibitors are very high.

\section{c) Trigger}

This phase is sensitive to environmental cues or signals. During this time there is a drastic decrease in inhibitors and a sharp rise in promoters.

\section{d) Germination (or) bud-break}

This phase is characterized by high promoters and low inhibitors leading to an increase in enzyme activity.

The length of each of these phases will depend on the genus and species. A diverse range of dormancy mechanisms has evolved in keeping with the diversity of climates and habitats in which they operate. A wide range of factors can therefore alter seed dormancy. For Ex: temperature, light, nitrate (or) naturally occurring chemical signals (ABA, terpenes, etc.,) in leachate from litter that covers the seeds in their habitat. However, there is an important distinction in the seeds response to these factors.

1. There are factors that are related to slow seasonal change. These factors, for eg., temperature, is integrated over time to alter the depth of dormancy and the sensitivity to other factors for $e g$., light.

2. There are other factors that indicate in a more immediate way that conditions are suitable for germination, for $e g$., light, which could be considered to terminate dormancy and therefore induce germination. Each of these factors therefore removes successive blocks to germination, but this process usually needs to be carried out in a set order for it to work.

\section{Types of dormancy}

The classification and degrees of dormancy found in plant vegetative structures have been defined as

\section{a. Exogenous dormancy}

Exogenous dormancy is caused by conditions outside the embryo. Dormancy is due to one (or) more unsuitable factors of the environment which are non-specific in their effect. It is a reduced growth response due to an external stimulus such as drought and cold. Removal of the stimulus results in a resumption of growth. In seeds, this term is equivalent to quiescence. Eg., Physical dormancy, chemical dormancy and mechanical dormancy.

\section{b. Para dormancy}

Dormancy is due to the physical factors (or) biochemical signal originating external to the affected structure for the initial reaction. It is a reduced growth response induced by a biochemical signal that is transported to a target tissue. This category could be identified by more rapid germination and normal seedling growth following excision of the embryo.

\section{c. Endogenous dormancy (Deep dormancy)}

Endogenous dormancy is caused by conditions within the embryo itself. It is due to an endogenous signal that results in growth suppression. It is regulated by physiological factors. Removal of the signal results in a resumption of growth. In seeds, this type is present if embryo excision fails to produce either more rapid germination (or) normal seedling growth. Eg., Physiological dormancy, morphological dormancy, morpho-physiological dormancy.

\section{Methods to overcome dormancy}

a. Scarification

I. It is a treatment by which the hard seed coat is ruptured (or) weakened.

II. It may be mechanical.

By such treatments, the expansion of the embryo is facilitated and oxygen gains entry into the seed.

\section{b. Mechanical scarification}

I. Several kinds of mechanical scarifications are possible like threshing of the seeds by machine, rupturing the seeds by hammer, cutting the seed coat by using a scalpel, etc.,

II. For mechanical scarification, seed coats can also be filed with a metal file, rubbed with sandpaper, nicked with a knife (or) cracked gently with a hammer to weaken the seed coat.
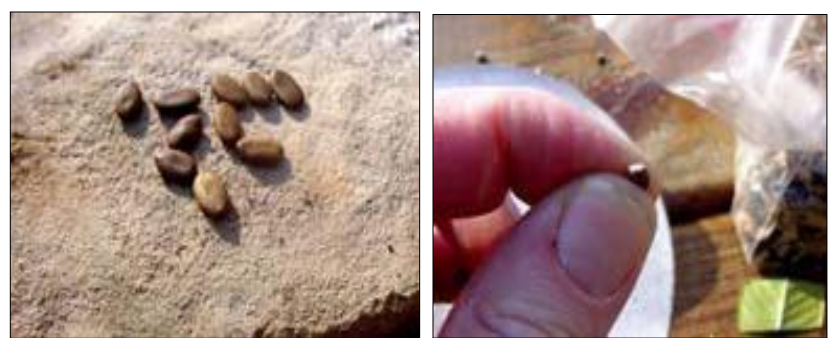
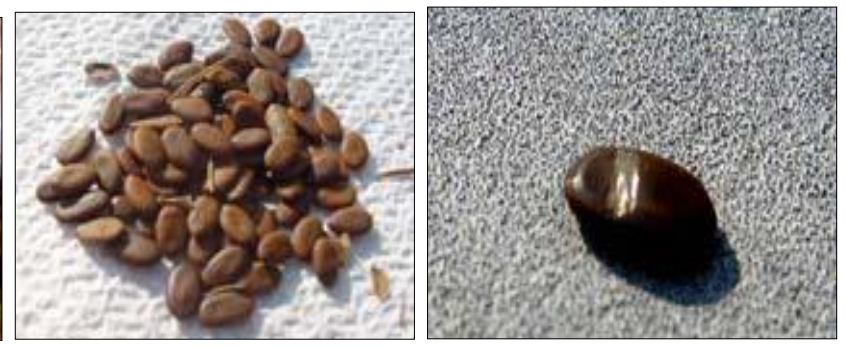

Fig 1: Mechanical scarification

\section{c. Hot water scarification}

i. Bring water to a boil $\left(212^{\circ} \mathrm{F}\right)$, remove the pot from the stove and place the seeds into the water. Allow the seeds to soak until the water cools to room temperature. Remove the seeds from the water and sow the seeds in the field.

ii. Following scarification, the seeds should be dull in appearance, but not deeply pitted or cracked as to damage the embryo. Scarified seeds do not store well and should be planted as soon as possible after treatment

\section{d. Chemical scarification}

i. The hard seed coat is ruptured by using chemicals like strong acids, organic solvents. In this method the seeds are soaked in strong acids (or) certain organic solvents for some time which helps in breaking the dormancy. In 
nature, the dormancy is broken by the slow decay of the seed coats.

ii. Scarification also can be forced, rather than waiting for nature to alter the seed coats. Commercial growers scarify seeds by soaking them in concentrated sulfuric acid. Seeds are placed in a glass container and covered with sulfuric acid. The seeds are gently stirred and allowed to soak for 10 minutes to several hours, depending on the species. When the seed coat has been modified (thinned), the seeds are removed, washed and sown.

iii. Sulfuric acid can, however, be very dangerous for an inexperienced individual and should be used with extreme caution. Vinegar is safer (but less effective treatment) and can be used for species that do not have an extremely hard seed coat. The technique is the same as with sulfuric acid.
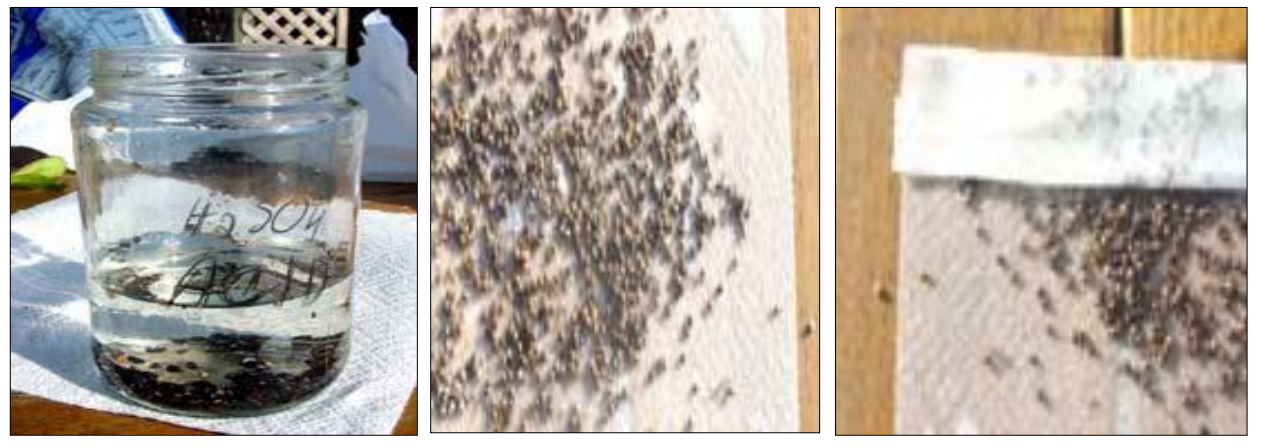

Fig 2: Chemical (Acid) scarification

\section{e. Stratification}

i. In warmer areas, give bulbs an artificial cold period to stimulate winter. Place bulbs in a refrigerator for about eight weeks to trick them into dormancy, so they can store energy for new growth.

ii. Another factor that can release seeds from dormancy is low temperature (or) chilling. Many seeds require a period of cold $\left(0\right.$ to $\left.10^{\circ} \mathrm{C}\right)$ while in a fully hydrated (imbibed) state in order to germinate. This is the process of exposing seeds to cold, moist conditions before sowing to trigger the germination process. It is necessary for seeds that have an immature or dormant embryo when harvested, which includes most perennials and woody plants. Some plants, such as Lettuce and Delphinium, become dormant when exposed to temperatures over $75^{\circ} \mathrm{F}$ for an extended period, these must be chilled to induce germination. In temperate-zone species, this requirement is of obvious survival value, since such seeds will germinate not in the fall, but only in the following spring.

iii. Chilling seeds to break their dormancy is a time honoured practice in horticulture and forestry and traditionally has been referred to as stratification. This term is derived from the old agricultural practice of allowing seeds with a chilling requirement to overwinter outdoors in layered mounds of moist soil. Today the seeds are simply stored in a refrigerator.

\section{Seed Dormancy}

Seed dormancy is inability of viable seed respond to favourable environment conditions i.e., temperature, water and oxygen for germination. The metabolic activity of dormant seed is similar to non-dormant seed. Dormancy is a mechanism to ensure the seed germination after optimum time. A dormant seed is not a 'failure'. The inability of certain seeds to germinate readily even when they are provided with all conditions required for germination.

\section{Advantages of seed dormancy}

- Favours seedling survival

- Creates a seed bank

- Seed dispersal by birds

- Synchronizes germination with seasons

\section{Types of seed dormancy}

\section{Primary seed dormancy (or) Innate dormancy}

The viable seed that does not germinate immediately after maturity under favourable conditions due to exogenous, endogenous (or) combination is considered as dormant and it starts germination after resting period. Freshly harvested, mature, water permeable dormant seeds are said to have primary dormancy, which has been induced with the involvement of Abscisic acid (ABA) during seed maturation on the mother plant.

\section{a) Physical dormancy (Seed coat dormancy)}

It is caused by seed coverings which are impervious to water and falls under the type of para dormancy. It acts as a safety mechanism by preserving the seed in the dry state even under warm conditions. Seeds exhibiting physical dormancy possess covering structures that physically prevent the seed from absorbing (or) imbibing water. Since water is necessary for germination, the seeds must be made permeable to water before germination can begin, which is usually achieved by chipping (or) cracking the seed coat. Eg. Rose, Pelargonium, Leguminaseae, Malvaceae, Chenopodiaceae, Geraniaceae, Convolvulaceae, etc.,

\section{Mechanisms to overcome physical dormancy}

i. By disrupting the seed coat and allowing water to enter.

ii. In nature, the seed coats are softened by the action of microorganisms passing through the digestive tracts of animals and birds.

iii. By mechanical abrasion.

iv. By alternate freezing (or) thawing.

v. By fire 


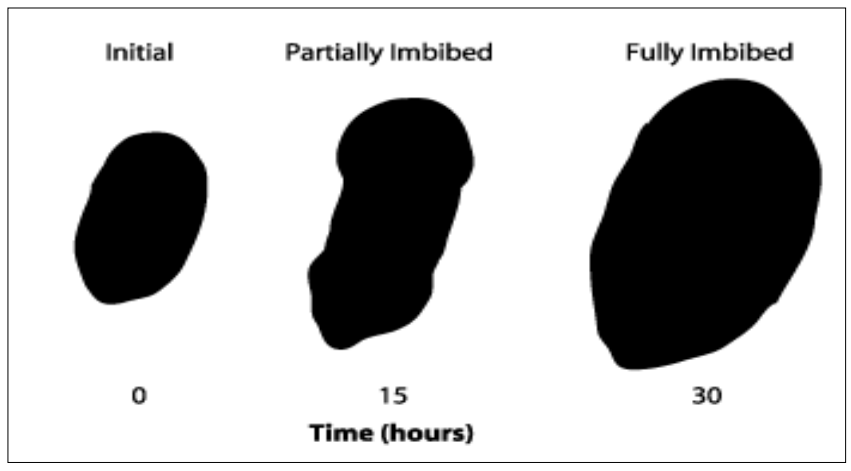

b) Mechanical seed dormancy (Hard seed dormancy)

Mechanical dormancy occurs when seed coats (or) other coverings are too hard to allow the embryo to expand during germination. In the past this mechanism of dormancy was ascribed to a number of species that have been found to have endogenous factors for their dormancy instead. These endogenous facts include physiological dormancy caused by low embryo growth potential. Eg. Chrysanthemum coronarium

\section{Mechanisms to overcome mechanical seed dormancy}

i. Cracking the structure covering the embryo (or) naturally by soil micro organisms.

\section{c) Chemical dormancy (Inhibitor dormancy)}

It is caused by the germination inhibitors which accumulate in the fruit and seed coverings during development. It is a type of para dormancy. Seeds of some plants contain compounds which inhibit their germination. Natural germination inhibitors are present in the pulp of the juice of fruit containing seed, seed coat, endosperm and embryo. Some inhibitors include ammonia, coumarin and parasorbic acid. In conclusion, diagnosing chemical dormancy is difficult. However, if the factor preventing germination is thought to be chemical and not physical (or) physiological, it may be leached (washed or soaked) from the seed (or) deactivated. Other chemicals that prevent germination are washed out of the seeds by rainwater (or) snow melt. Eg. Gladiolus.

\section{d) Morphological dormancy}

It is also called as rudimentary embryo dormancy (or) undeveloped embryo dormancy. It occurs when seeds are shred from the parent plant when their embryos are not fully developed. It is a type of para dormancy (or) endo dormancy. The embryo begins to enlarge after the seed imbibes water and germination begins. It can be due to two types of embryo, rudimentary embryos which are pro-embryos embedded into massive endosperm such as observed in the families of Ranunculaceae, Papaveraceae and Araliaceae (or) under developed embryos. Eg. Delphinium, Fraxinus excelsior(Oleaceae) seeds exhibit morpho physiological dormancy.

Table 1: Physiological dormancy has three levels: deep, intermediate and non-deep

\begin{tabular}{|c|c|c|}
\hline Physiological dormancy deep & ological dor & Physiological dormancy non-deep \\
\hline $\begin{array}{l}\text { Embryos excised from physiological } \\
\text { dormancy-deep seeds either don't grow } \\
\text { or will produce abnormal seedlings. }\end{array}$ & $\begin{array}{l}\text { Embryos excised from physiological dormancy- } \\
\text { intermediate seeds produces normal seedlings. }\end{array}$ & $\begin{array}{l}\text { Great majority of seeds have non-deep } \\
\text { physiological dormancy. Embryos excised from } \\
\text { these seeds produce normal seedlings. }\end{array}$ \\
\hline $\begin{array}{r}\mathrm{GA}_{3} \text { treatmen } \\
\mathrm{d}\end{array}$ & GA3 promotes germi & $\mathrm{GA}_{3}$ \\
\hline $\begin{array}{l}\text { Cold (or) warm stratification are } \\
\text { required to break dormancy. } \\
\text { Eg. Acer platanoides (Sapindaceae), } \\
\text { Ericaceae } \\
\end{array}$ & $\begin{array}{c}\text { Seeds require 2-3 months of cold stratification. Dry } \\
\text { storage (after-ripening) can shorten the cold } \\
\text { stratification period. Eg. Acer pseudoplatanus } \\
\text { (Sapindaceae), Aceraceae }\end{array}$ & $\begin{array}{l}\text { Depending on species dormancy can also be } \\
\text { broken by scarification, after-ripening in dry } \\
\text { storage and cold }\left(0-10^{\circ} \mathrm{C}\right)(\text { or }) \text { warm }\left(>15^{\circ} \mathrm{C}\right) \\
\text { stratification. }\end{array}$ \\
\hline
\end{tabular}

\section{Mechanisms to overcome morphological dormancy}

By subjecting the seeds to temperatures which favour embryo development (or) enlargement, morphological dormancy can be removed. Also by treating with chemicals such as potassium nitrate (or) gibberellic acid morphological dormancy can be removed.

\section{Physiological dormancy}

Physiological dormancy is the most abundant form and is found in seeds of gymnosperms and all major angiosperm clades. It is the most prevalent dormancy form in temperate seed banks and the most abundant dormancy class "in the field". It is also the major form of dormancy in most seed model species "in the lab", including Arabidopsis thaliana, Helianthus annuus, Lactuca sativa, Lycopersicon esculentum, Nicotiana sps, Avena fatua and several other cereals. Physiological dormancy prevents embryo growth and seed germination until chemical changes occur. These chemicals include inhibitors that often retard embryo growth to the point where it is not strong enough to break through the seed coat or other tissues. It is a general type of primary dormancy in freshly harvested seeds from herbaceous plants. It is a type of para dormancy. Physiological dormancy is indicated when an increase in germination rate occurs after application of gibberellic acid (or) dry after ripening (or) dry storage increases germination. It is also indicated when dormant seed embryos are excised and produce healthy seedlings (or) when up to 3 months of cold $\left(0-10{ }^{\circ} \mathrm{C}\right.$ ) (or) warm $\left(=15^{\circ} \mathrm{C}\right)$ stratification increases germination (or) when dry after-ripening shortens the cold stratification period required. In some seeds physiological dormancy is indicated when scarification increases germination. Seeds are classified as having deep physiological dormancy under these conditions. Application of $\mathrm{GA}_{3}$ does not increase germination, when excised embryos produce abnormal seedlings, when seeds require more than 3 months of cold stratification to germinate. Eg. Nymphea alba, Iris, Dianthus. Ericaceae (Sapindaceae), Aceraceae stratification. 


\section{Mechanisms to overcome physiological dormancy \\ Drying}

- Some plants including a number of grasses and those from seasonally arid regions need a period of drying before they germinate, the seeds are released but need to have a lower moister content before germination can begin.

- If the seeds remain moist after dispersal, germination can be delayed for many months (or) even years.

- Many herbaceous plants from temperate climate zones have physiological dormancy that disappears with drying of the seeds.

- Other species will germinate after dispersal only under very narrow temperature ranges, but as the seeds dry they are able to germinate over a wider temperature range.

\section{Photo dormancy}

Light sensitivity affects germination of some seeds. These photoblastic seeds need a period of darkness (or) light to germinate. In species with thin seed coats, lightmay be able to penetrate into the dormant embryo. The presence of light (or) the absence of light may trigger the germination process, inhibiting germination in some seeds buried too deeply (or) in others not buried in the soil. Eg. Begonia (Light), Verbena (Dark).

\section{Thermo dormancy}

Seed has sensitivity to heat or cold. Some seeds including Cocklebur (Xanthium stromarium) and Amaranth germinate only at high temperatures $\left(30^{\circ} \mathrm{C}\right.$ or $\left.86^{\circ} \mathrm{F}\right)$. Many plants which possess thermo dormancy seeds, they germinate at early to mid-summer when the soil temperature is warm. Other seeds which need cool soils to germinate like celery are inhibited when soil temperatures are too warm. Often thermo dormancy requirements disappear as the seed ages or dries. Dormancy in most woody plants can be induced by short photo periods even at temperatures of $70^{\circ}$ to $200^{\circ} \mathrm{F}$. Japanese larch, Yellow poplar and others become dormant after about 15 short days and many species cease growth after about 30 days, but plants like Monterey pine (Pinus radiata) require several months of short photo periods. Depth of dormancy is greater in some species such as Catalpa, than in others. Catalpa requires a cold period to break dormancy, but even after a full year dormancy in birch can be broken by long days alone.

\section{f) Physiological embryo dormancy}

It is characterized by factors which directly affect the embryo. It produces an abnormal seedling at germination process. It is a type of para dormancy (or) endo dormancy. Seeds have deep physiological dormancy, if application of $\mathrm{GA}_{3}$ does not increase germination, excised embryos produce abnormal seedlings, seeds require more than 3 months of cold stratification to germinate.

\section{g) Embryo dormancy (embryo component of non-deep physiological dormancy)}

A dormant embryo is characterized by high ABA/GA ratio, high ABA sensitivity and low GA sensitivity. Embryo dormancy release involves remodelling of hormone biosynthesis and degradation towards a low ABA/GA ratio, a decrease in ABA sensitivity and an increase in GA sensitivity. Thus ABA dominates the embryo dormancy program and GA the embryo germination program. A non-dormant embryo is characterized by increased growth potential, the ability for cell extension growth and the ability to induce the release of coat dormancy.

\section{h) Combinational dormancy}

Seeds have both morphological and physiological dormancy. Morpho-physiological dormancy occurs when seeds with under developed embryos have physiological components to dormancy. These seeds therefore require dormancy breaking treatments as well as a period of time to develop fully grown embryos. Eg. Iris, Cercis.

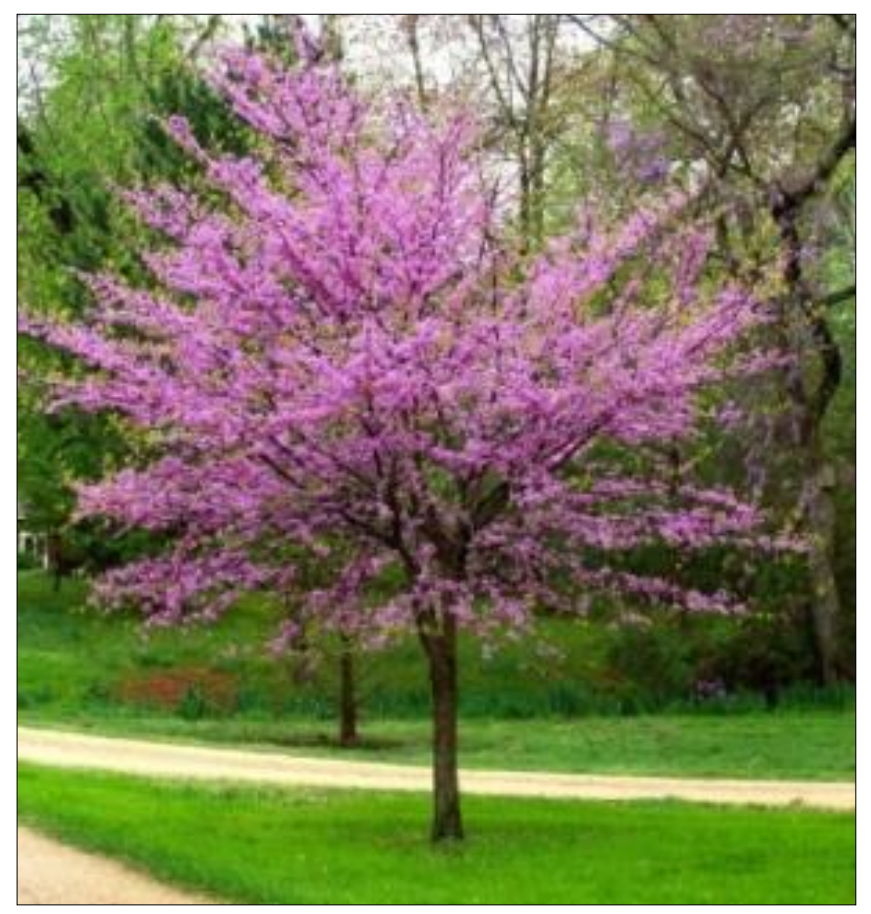

Fig 4: Cercis canadensis exhibits combinational dormancy

\section{i) Double dormancy}

It is a combination of two or more kinds of dormancy. It falls under both para dormancy and endo dormancy. This type of dormancy is a characteristic of species of trees and shrubs with hard seed coats. Some seeds, however, need more than one special treatment to begin their growth cycle and this is called double dormancy. Eg. Ilex, Taxus, Viburnum, Lilies and tree Peonies need a warm period (68$86^{\circ} \mathrm{F}$ ) of three months in which the root develops, followed by stratification for 1-3 months which triggers stem development, before emergence of the growing tip will occur.

\section{j) Secondary seed dormancy}

It can be induced in seeds with non-deep physiological dormancy after seed dispersal and is often associated with annual dormancy cycles. Secondary dormancy prevents the seed from germinating after it absorbs water. It appears that the development of secondary dormancy is reverse of after ripening. It is caused by temperature extremes, prolonged darkness, prolonged light, water stress, oxygen extremes, etc., It has been demonstrated that secondary dormancy may be caused by changes in the seed coat or embryo itself. In most of the cases it can be overcome by chilling treatment. Vegetable and flower genera with seeds that commonly exhibit secondary dormancy include thermo dormancy in Apius lactuca and light induced dormancy in Nigella sativa 


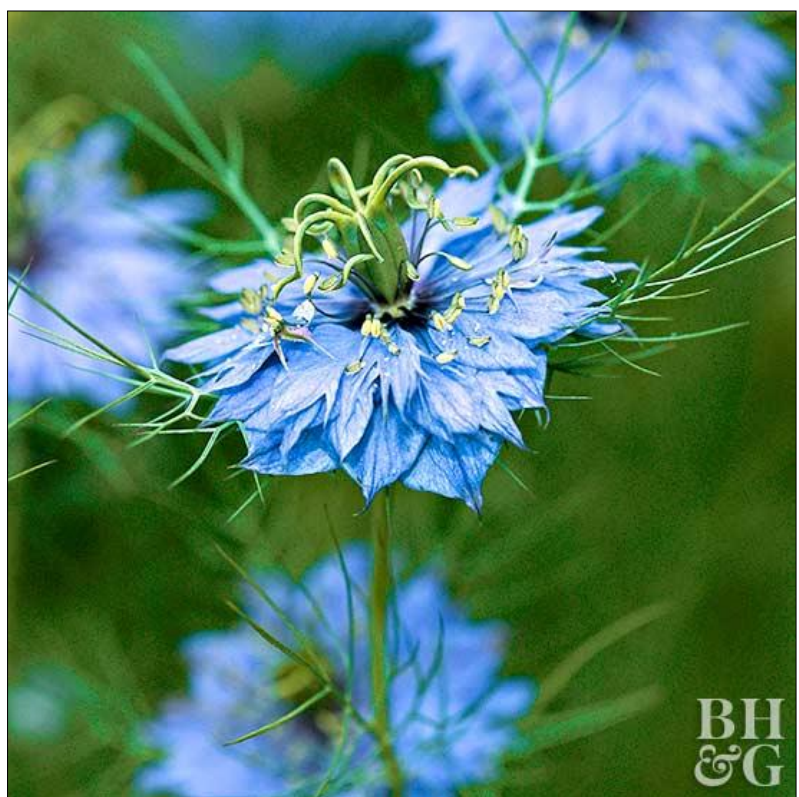

Fig 5: Nigella sativa exhibits secondary dormancy
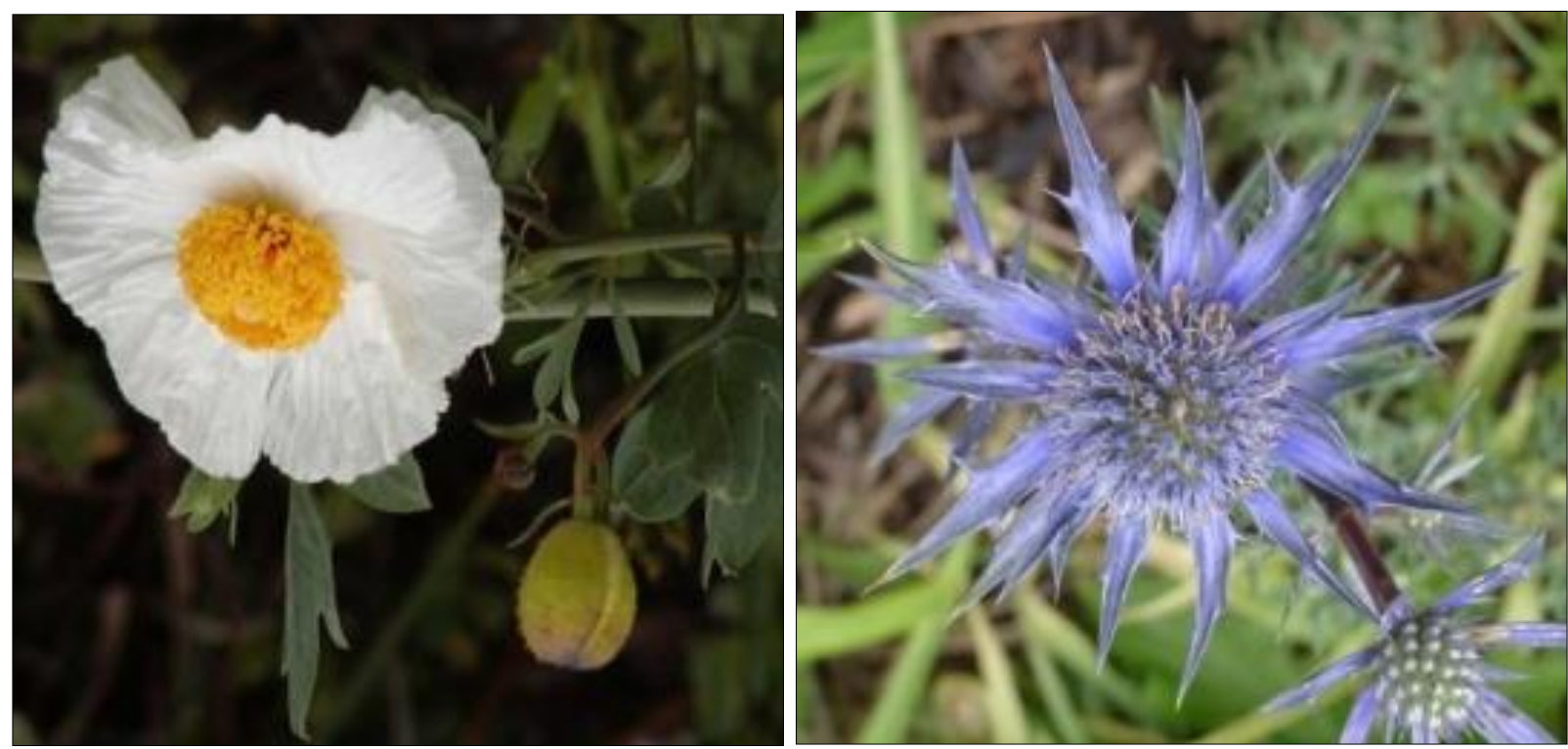

Fig 6: Romneya and Eryngium exhibits combinational dormancy
Factors affecting the seed dormancy

\section{Environmental factors}

\section{a. Light duration and quality}

The external factor that plays an important role in breaking seed dormancy is light. Many seeds have a light requirement for germination, which may involve only a brief exposure as in the case of lettuce, an intermittent treatment $(E g$. Kalanchoe) or even a specific photoperiod involving short or exhibit seed coat dormancy and removal of the outer tissues of the seed allows the embryo to germinate in the absence of the radical to penetrate the seed coat. This penetration often involves some enzymatic weakening of the enclosing tissues.

\section{b. Temperature}

Temperature plays a significant role in the annual cycling between growth and dormancy of the herbaceous perennial chrysanthemum (Chrysanthemum morifolium ramat). After long days. Phytochrome is the main sensor for light regulated seed germination. Interestingly, all light requiring seeds light. The effect that light has on the embryo is thus to enable

\section{Combinational dormancy}

Combinational dormancy occurs in some seeds, where dormancy is caused by both exogenous (physical) and endogenous (physiological) conditions. Sequential combinations of dormancy releasing treatments required to overcome this dormancy. Eg. Scarification followed by cold stratifications. Some Iris species have both hard impermeable seed coats and physiological dormancy. Flower genera containing seeds that have exogenous dormancy and require seed coat scarification. Eg. Abutilon, Convolvulus, Lespedeza, Amorpha Indigofera Lupinus, Baptisia, Geranium, Thermopsis, Cistus, Lathyrus, etc., Flower genera containing seeds that have endogenous morphological dormancy include Eg. Anemone, Gentiana, Primula, Apium, Hemerocallis, Ranunculus, Cyclamen, Hosta, Romneya, Eryngium, Papaver, etc., Vegetable and flower genera containing seeds that have endogenous, non-deep physiological dormancy and require light or darkness for germination include light required Amaranthus, Catharanthus, Gaillardia, Nicotiana, Alyssum, Celosia, Helenium, Petunia etc., and dark required Allium, Nigella, Achillea, Capsicum, Cyclamen, Phacelia, Nemophilla, Antirrhinum, Cleome, Exacum schizanthus, etc. exposure to high summertemperatures, cool temperature triggers dormancy. Cessation of flowering and rosette formation by cessation of elongation are the characteristics of dormant plants and can be stimulated by exogenous ethylene. Thus, the ethylene response pathway may be involved in temperature induced dormancy of chrysanthemum. Growth cessation and dormancy are adaptive responses enabling survival during seasons when environmental conditions are most threatening (Vegis, 1964). Rosette formation is the main adaptive response, maintaining the viability of meristems under winter cold, similar to the formation of terminal buds in woody perennials. In chrysanthemum, first high temperatures and then cool temperatures are significant environmental cues for the formation of rosettes before winter (Sumitomo et al., 2008).

\section{Physical factors}

\section{a. Seed coat factors}

A hard seed coat can cause dormancy in three ways:

i. By being impermeable to water 
ii. By being impermeable to oxygen

iii. By mechanically restricting the growth of the embryo

\section{Seed coats impermeable to water}

Seeds of many plants including the leguminosae, malvaceae, chenopodiaceae, convolvulaceae and solanaceae have very hard seed coats. Such seed coats are impermeable to water.

\section{Seed coat impermeable to oxygen}

In some species the hard seed coat is completely impermeable to oxygen. Such seeds would not germinate unless they have undergone the period of dormancy during which the permeability of the seed coats will gradually increase.

\section{Mechanically resistant seed coats}

In certain wild plants, the hard seed coat acts as a physical barrier to the expansion of the embryo.

\section{b. Embryonic factors \\ i. Immature embryo}

In certain species of Orchidaceae, Orobanchaceae, Fraxinus and Ranunculus, the seeds are liberated at a stage when the embryo is not fully developed. This type of dormancy is a natural consequence of the presence of an incompletely developed embryo in the seed.

\section{b. Chemical inhibitors}

In certain species specific chemical substances that prevent germination occur in the seed coats, endosperm or the embryo. They are reduced or eliminated by leaching with water or adsorption of water. Chemicals used to break dormancy are Thiourea (Gladiolus), Ethylene Chlorohydrin (Gladiolus), Dinitrophenol, etc.

\section{Significance of seed dormancy}

- The state of dormancy equips seeds to escape detrimental effects of adverse condition.

- During dormancy, physiological activity may be suspended which results in slow down the process of seed deterioration. This increases the chance of survival of seeds.
- It restricts pre-mature germination of seeds within ears/pods (vivi-pary) when crops are exposed to a wet weather favourable for germination just after harvest.

\section{After ripening}

Various external factors release the seed from dormancy and dormant seeds typically respond to more than one condition. Many seeds lose their dormancy when their moisture content is reduced to a certain level by drying. This method of breaking seed dormancy is called after ripening and is usually performed in a special drying oven. On the other hand, if the seed becomes too dry (5\% water content or less), the effectiveness of after ripening is diminished. Eg. Tulips, iris, poplar, pines, etc.

\section{Bud dormancy}

Bud is an undeveloped or embryonic shoot and normally occurs in the axil of a leaf or at the tip of stem. Once formed bud may remain for sometime in condition or it may form a shoot immediately. Buds may be specialized to develop flowers or short shoots or may have the potential for general shoot development. The buds of many woody plants, especially in temperate or cold climates, are protected by a covering of modified leaves called scales, which tightly enclose the more delicate parts of the bud.

Many bud scales are covered by a gummy substance which serves as added protection. When the bud develops, the scales enlarge somewhat but usually just drop-off, leaving on the surface of the growing stem a series of horizontally elongated scars. The minute under developed leaves in such buds are often excessively hairy. In many of the latter, buds are even more reduced, often consisting of undifferentiated masses of cells in the axils of leaves. A terminal bud occurs on the end of a stem and lateral buds are found on the side. Since buds are formed in the axil of leaves, there distribution on the stem is the same as that of leaves. In many plants buds appear in unexpected places these are known as adventitious buds.

\section{Types of buds}

Buds are often useful in the identification of plants, especially for woody plants in winter when leaves have fallen. Buds may be classified and described according to different criteria viz., location, status, morphology and function.

Table 2: Classification of buds based on location, status, morphology and function

\begin{tabular}{|c|c|c|c|}
\hline For location & For status & For morphology & For function \\
\hline $\begin{array}{c}\text { Terminal - when } \\
\text { located at the tip of } \\
\text { a stem }\end{array}$ & $\begin{array}{c}\text { Accessory - for secondary buds formed } \\
\text { besides a principal bud }\end{array}$ & $\begin{array}{c}\text { Sally (or) covered - when scales, also } \\
\text { referred to as perule, cover and protect } \\
\text { the embryonic parts }\end{array}$ & $\begin{array}{c}\text { Vegetative - if only containing } \\
\text { vegetative pieces: embryonic shoot with } \\
\text { leaves (a leaf bud is the same) }\end{array}$ \\
\hline $\begin{array}{c}\text { Axillary - when } \\
\text { located in the axil } \\
\text { of a leaf }\end{array}$ & $\begin{array}{c}\text { Resting - for buds that form at the end of } \\
\text { growth season, which will lie dormant until } \\
\text { onset of the next growth season }\end{array}$ & Naked - when not covered by scales & $\begin{array}{c}\text { Reproductive - if containing embryonic } \\
\text { flower (a flower bud is the same) }\end{array}$ \\
\hline
\end{tabular}

Table 3: Classification of buds based on location, status, morphology and function

\begin{tabular}{|c|c|c|c|}
\hline For location & For status & For morphology & For function \\
\hline $\begin{array}{c}\text { Adventitious - when occurring } \\
\text { elsewhere for example on trunk or } \\
\text { on roots }\end{array}$ & $\begin{array}{c}\text { Dormant (or) latent - for buds whose growth has been } \\
\text { delayed for a rather long time. The term is usable as } \\
\text { synonym of resting }\end{array}$ & $\begin{array}{c}\text { Hairy - when also } \\
\text { protected by hairs }\end{array}$ & $\begin{array}{c}\text { Mixed - if containing both } \\
\text { embryonic leaves and } \\
\text { flowers }\end{array}$ \\
\hline & $\begin{array}{c}\text { Pseudo terminal - for an axillary bud taking over the } \\
\text { function of terminal bud }\end{array}$ & & \\
\hline
\end{tabular}

Stages of bud dormancy

\begin{tabular}{|c|c|c|}
\hline Pre-dormancy & True dormancy & Post-dormancy \\
\hline $\begin{array}{c}\text { Reversible; bud will grow if conditions turn } \\
\text { favourable }\end{array}$ & $\begin{array}{c}\text { Irreversible; bud cannot grow until chilling } \\
\text { requirement has been met }\end{array}$ & $\begin{array}{c}\text { Bud is capable of growing (has met chilling } \\
\text { requirement) }\end{array}$ \\
\hline
\end{tabular}




\section{Role of growth regulators in bud dormancy}

\section{i. $\mathbf{A B A}$}

ABA mediates the conversion of the apical meristem in to a dormant bud. The newly developing leaves growing above the meristem become converted into stiff bud scales that wrap the meristem closely and will protect it from mechanical damage during winter. The external application of ABA to buds of growing seedlings caused them to become dormant. When ABA was measured by physical means, it was found that $\mathrm{ABA}$ in short days exposed leaves is not higher than those that had remained under long days.

On the other hand physical assay methods have confirmed the presence of high levels of ABA in the dormant buds of several species and have shown that these levels progressively decline throughout the winters. According to these findings ABA was synthesized in the plant, in the response of some environmental trigger and this ABA travelled to the buds and induced them to go dormant. In the temperate zone trees, short days induced the leaves to synthesize more ABA and export it to the buds.

\section{ii. Benzyl adenine (BA)}

In green house roses like Regal Gold, dormancy is removed by applying BA along with adenine $(0.5 \%)$.

\section{iii. Gibberellic acid}

Exogenous applications of gibberellins have been shown to relieve certain types of dormancy including physiological, photo and thermo dormancy.

\section{iv. Ethylene}

It will not promote germination in quiescent seeds and will not alter the requirement for the rest period. It overcomes dormancy in many cases where physical dormancy is present. In addition, the gaseous plant hormone ethylene has been shown to play a role in the induction of bud dormancy in birch (Betula pendula).

\section{Conclusion}

Seed dormancy may pose problems in the determination of seed germination immediately after harvest. In such cases, we have to resort some effective treatments to overcome the dormancy. A knowledge of dormancy not only helps in understanding the survival of seed under natural condition, it also provides cheap and highly effective means for the protection of crop produce from deterioration due to preharvest sprouting and enables us to conduct reliable germination tests in such species that exhibit dormancy.

\section{References}

1. Evenari M. Germination inhibitors. Botanical Reviews. 1949; 15:153-194

2. Katsuhiko S, Takako N, Shigeru S, Tamotsu H. Involvement of the ethylene response pathway in dormancy induction in chrysanthemum. Journal of Experimental Botany. 2008; 59(15):4075-4082

3. Malcolm BW. Advanced plant physiology book

4. Robert LG. Seed dormancy in commercial vegetable and flower seeds.

5. Vegis A. Dormancy in higher plants. Annual Review of Plant Physiology. 1964; 15:185-224.

6. Wareing PF, Foda HA. Growth inhibitors and dormancy in Xanthium seed. Physiologia Plantarum. 1957; 10:266280. 